\title{
INVESTIGATION OF NATURAL CONVECTION HEAT TRANSFER AT CONSTANT HEAT FLUX ALONG A VERTICAL AND INCLINED PLATE
}

\author{
Sebiha Yıldız
}

\section{ABSTRACT}

It is a common phenomenon that the devices that are exposed to constant heat fluxes are cooled at natural atmospheric environments. However, it is required to know the surface temperature in these devices. In this study, the cooling of a plate $\left(1 \mathrm{~m}\right.$ in height and $1 \mathrm{~m}$ in width) which is oriented vertical, and also $20^{\circ}$ - and $45^{\circ}$-inclined from the vertical (downward-facing surface), at the constant heat flux of $1000 \mathrm{Wm}^{-2}$ at atmospheric natural convection conditions is investigated. The local temperature values at the vertical center of the plate are calculated using the correlation in Vliet [1]'s experimental study and computer analyses and compared to those results. The results show that the surface temperature values of the plate at the inclination angle of $45^{\circ}$ are relatively higher than those of the plate at the vertical state and those of the $20^{\circ}$-inclined plate.

Keywords: Natural Convection, Computer Analysis, Vertical and Inclined Plate, Downward-Facing Surface, Constant Heat Flux, Air

\section{INTRODUCTION}

Natural convection heat transfer is a type of heat transfer which is common in the cooling processes of the photovoltaic panels and electronic chips, etc. This type of heat transfer is caused by the buoyancy force induced by the density gradients which result from temperature differences in the fluid. When compared with forced convection, as there is not a fan-induced motion to the fluid on the plate involved, problems such as nonfunctioning fans and the noise or the electricity cost of the fan are not in question.

There is a limited number of studies where the natural convection heat transfer along vertical and inclined plates at constant heat fluxes are investigated in the literature. Vliet [1] carried out an experimental investigation of the natural convection heat transfer along a vertical and inclined plate. The plate was $0.9 \mathrm{~m}$ in width and $1.2 \mathrm{~m}$ in height and it was stainless steel. The surface temperature of the heated plate was measured. The back-surface is isolated against heat transfer. Vliet [1] also used air on the inclined plate (upward-facing surface) in his experiments. He reported that the radiation heat loss also was taken into consideration for. Vliet [1] proposed the following expression for the convection heat transfer coefficient in laminar natural convection along a vertical and inclined plate:

$$
N u_{y}=0.60\left(G r_{y}^{*} P r\right)^{0.2}
$$

Here, the Nusselt Number is

$$
N u_{y}=h_{y} y / k
$$

and the modified local Grasof number is

$$
G r_{y}^{*}=\left(g \beta \dot{q}_{s} y^{4}\right) /\left(k v^{2}\right)
$$

Reference [2] suggests that Equation (1), which is proposed for laminar regime, can be used for both upward- and downward-facing surface of the inclined plates by replacing gravity constant $g$ with $g \cos \theta$ in Grasof number. In his study, Vliet [1] found out that the inclination angle is significant for the turbulent regime to start.

\footnotetext{
This paper was recommended for publication in revised form by Regional Editor Bekir Yilbas

${ }^{1}$ Department of Mechanical Engineering, Yildiz Technical University, Istanbul, TURKEY

"E-mail address: syildiz@yildiz.edu.tr

Manuscript Received 28 February 2018, Accepted 4 July 2018
} 
He suggested the following expression for the turbulent flow:

$$
N u_{y}=0.30\left(G r_{y}^{*} P r\right)^{0.24}
$$

Vliet and Liu [3] investigated the natural convection heat transfer along a vertical plate in water. For turbulent heat transfer at the values of $2 \times 10^{13}<G r_{y}^{*} P r<10^{16}$, they proposed the following expression:

$$
N u_{y}=0.568\left(G r_{y}^{*} P r\right)^{0.22}
$$

Vliet and Ross [4] carried out their experiments in order to investigate turbulent natural convection of air at atmospheric conditions along an inclined plate's heated surfaces (upward and downward) as well as experiments along a vertical plate. The heated plate is $1.83 \mathrm{~m}$ in width and $7.32 \mathrm{~m}$ in height and they created constant surface heat flux via electrical resistance heating. Dotson [5]'s following correlation, which are mentioned in Vliet and Ross [4], are suggested for both laminar regimes (the heated upward- and downward-facing surfaces):

$$
N u_{y}=0.55\left(G r_{y}^{*} P r\right)^{0.20}
$$

here, the gravity component along the plate is $g \cos \theta$ and the inclination angle of the plate to the vertical is $\theta$. They suggested the following expression for the turbulent flow:

$$
N u_{y}=0.17\left(G r_{y}^{*} P r\right)^{0.25}
$$

They stated that a good solution could be obtained by replacing g with $g \cos ^{2} \theta$ in Grashof number for the downward-facing surface of the plate; while, they did exclude the inclination angle of the plate in Grashof number for the upward-facing surface of the plate.

Fussey and Warneford [6] studied free convection in water on a downward facing inclined plate with uniform heat flux. They developed the correlations for the laminar and turbulent flow. Lim and Chung [7] carried out experimental investigations of natural convection heat transfer along inclined plates. Fahimini et al. [8] carried out computational analyses of laminar natural convection along vertical plates. Khan and Aziz [9] also carried out computational analyses of natural convection status of nano-fluids along a vertical plate at constant heat flux. Moreover, Lin et al. [10] implemented a numerical investigation of free convection on a positively and slightly negatively inclined upward-facing plate at arbitrary inclination with uniform heat flux, which provided correlations and numerical results. Another investigation made by Guha and Pradhan [11] was concluded by a unified integral theory of laminar natural convection over horizontal and vertical surfaces at arbitrary inclination. They obtained new algebraic correlations yielding the Nusselt number as explicit functions of Grashof number, Prandtl number and inclination angle.

During the review of the literature of this study, it was found out that although it is known that many devices operate at atmospheric conditions on surfaces with constant heat flux, there are not many studies considering that. It is important to know the surface temperature values of the devices which are exposed to constant heat flux on the surface. In these kind of devices, an over increase of surface temperature can deteriorate the device's performance as in photovoltaic panels [12] or result in the burning of the device. For these reasons, it is vital to determine the surface temperature values of the surfaces which are exposed to constant heat flux. In this study, natural convection heat transfer along a plate which was oriented vertical, and also $20^{\circ}$ - and $45^{\circ}$-inclined from the vertical (downward-facing surface) at the constant heat flux of $1000 \mathrm{Wm}^{-2}$ was investigated. The local temperature values along the vertical center line of the plate were calculated using the correlation in Vliet [1]'s experimental study and computational analyses and the results were compared to one another.

\section{Determination of the plate surface temperature using the existing correlation}

At this point, it is necessary to determine the surface temperature of the plate under constant heat flux. To do this, the thermosphysical properties of air must be written at film temperature in the correlation. This being the case, surface temperature iterations must be made for each of the $0.1 \mathrm{~m}$ intervals from the bottom edge of the plate. 
For each of the point at which the temperature will be determined, a local heat transfer coefficient $\left(h_{y}\right)$ is guessed and the calculations are pursued until it equals with the calculated local heat transfer coefficient using Eq. (1) with the estimated.

$$
T_{y}-T_{\infty}=\dot{q}_{s} / h_{y}
$$

Here $\dot{q}_{s}$ is the constant heat flux on the surface of the plate and $T_{\infty}$ is ambient temperature, $h_{y}$ is the guessed local heat transfer coefficient at any distance y and $T_{y}$ is the local surface temperature of the plate. The film temperature for air can be specified as follows:

$$
T_{f}=\left(T_{y}-T_{\infty)}\right) / 2+T_{\infty}
$$

As the air is taken as an ideal gas, the volumetric thermal expansion coefficient in Grashof number can be written as follows:

$$
\beta=1 / T_{f}
$$

Modified Rayleigh number

$$
R a_{y}^{*}=\left(G r_{y}^{*} P r\right)
$$

Modified Grashof number $\left(G r_{y}^{*}\right)$ is taken from Equation (3) and Prandtl number

$$
\operatorname{Pr}=v / \alpha
$$

is as shown above.

\section{THEORETICAL ANALYSIS}

\section{Governing equations}

In this study, steady two-dimensional natural convection conditions along a vertical and inclined plate at constant heat flux are taken into consideration. As can be seen in Figure 1, coordinate $\mathrm{x}$ is the normal of the surface of the plate and coordinate $y$ is along the surface of the plate. The coordinate system is placed at the bottom edge of the plate so as to align it along the vertical center line of the plate (Figure 1a and 1b).

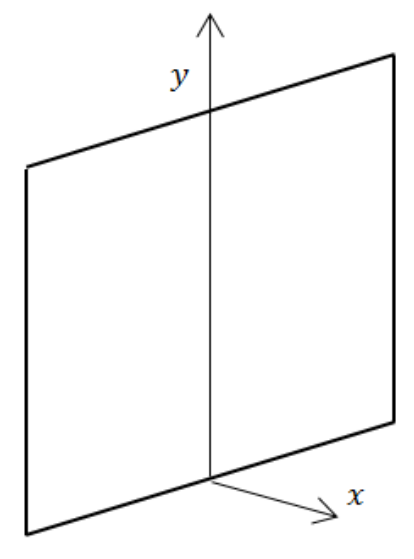

(a)

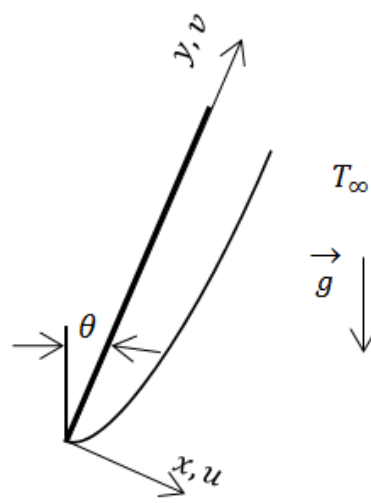

(b)

Figure 1. (a) Vertical plate; (b) Natural convection thermal boundary layer on an inclined plate. 
In the present study, the inclination angle of $y$-axis from the vertical is $\theta$. Therefore, the effect of the gravitational acceleration on the flow field has two components: $\mathrm{x}$-component $(g \sin \theta)$ and $y$-component $(g \cos \theta)$. Laminar flow continuity, momentum and energy equations in natural convection boundary layers are as follows $[8,13,14,15]$ :

\section{Continuity}

$$
\frac{\partial u}{\partial x}+\frac{\partial u}{\partial y}=0
$$

$x$-Momentum

$$
\rho\left(u \frac{\partial u}{\partial x}+v \frac{\partial u}{\partial y}\right)=-\frac{\partial P}{\partial x}+\mu\left(\frac{\partial^{2} u}{\partial x^{2}}+\frac{\partial^{2} u}{\partial y^{2}}\right)-g \sin \theta\left(\rho_{\infty}-\rho\right)
$$

$y$-Momentum

$$
\rho\left(u \frac{\partial v}{\partial x}+v \frac{\partial v}{\partial y}\right)=-\frac{\partial P}{\partial y}+\mu\left(\frac{\partial^{2} v}{\partial x^{2}}+\frac{\partial^{2} v}{\partial y^{2}}\right)+g \cos \theta\left(\rho_{\infty}-\rho\right)
$$

Energy

$$
u \frac{\partial T}{\partial x}+v \frac{\partial T}{\partial y}=\alpha\left(\frac{\partial^{2} T}{\partial x^{2}}+\frac{\partial^{2} T}{\partial y^{2}}\right)
$$

The boundary conditions of the problem:

$$
\begin{gathered}
\text { For } x=0, u=v=0, \quad-k \frac{\partial T}{\partial x}=\dot{q}_{s}-\dot{q}_{r} \\
\text { For } x \rightarrow \infty, u=v=0, \quad T=T_{\infty}
\end{gathered}
$$

In this study, radiation heat loss from the surface of the plate is taken into consideration. This being the case, the radiation effect at the boundary conditions is also taken into consideration. Here, $\dot{q}_{s}$ is the constant heat flux on the surface; $\dot{q}_{r}$ is the radiation heat loss on the surface and $T_{\infty}$ is the ambient temperature. The above equations from (13) to (16) are solved along with the equations (17) and (18) in order to obtain the expression of temperature $T(x, y)$ at thermal boundary layer. In this study, air is assumed as an ideal gas while solving these equations.

Surface to surface model in [16] was deployed in calculating the radiation heat transfer loss at the surface. The following generic form can be used for the radiosity equation:

$$
J_{k}=\varepsilon_{k} \sigma T_{k}^{4}+\left(1-\varepsilon_{k}\right) \sum_{j=1}^{N} F_{k j} J_{j}
$$

The above equation depicts the radiosity from surface $\mathrm{k}$ into a system with a number of other surfaces $(\mathrm{N})$ which all radiates a certain amount of heat. Subscripts are the surfaces, $\varepsilon_{k}$ is the emissivity of the surface $\mathrm{k}, \mathrm{F}$ is the view factor obtained with the Equation $(20), J_{k}\left(\mathrm{~W} \mathrm{~m}^{-2}\right)$ is the energy that radiates (or radiosity) from the surface $\mathrm{k}, \sigma$ is Boltzmann's constant $\left(\sigma=5.67 \times 10^{-8} \mathrm{~W} \mathrm{~m}^{-2} \mathrm{~K}^{-4}\right)$, and $\mathrm{T}(\mathrm{K})$ is the surface temperature. The following equation is the view factor between the two finite surfaces $\mathrm{i}$ and $\mathrm{j}$

$$
F_{i j}=\frac{1}{A_{i}} \int_{A_{i}} \int_{A_{j}}\left(\frac{\cos \alpha_{i} \sin \alpha_{j}}{\pi R^{2}}\right) d A_{i} d A_{j}
$$


A is the area of a surface and $\alpha$ is the angle formed out of the normal of the surface towards the other surface. The $\mathrm{R}$ term is the distance between the surfaces.

\section{Computational analysis}

Fluent 16.2 is used in the computational analyses. The equations are assumed steady, laminar, incompressible and two-dimensional for natural convection boundary layer along a vertical and downward-facing inclined surface. The plate is $1 \mathrm{~m}$ in length and $1 \mathrm{~m}$ in width. The radiation effect is taken into consideration in the analysis and the emissivity is taken as $\varepsilon=0.05$. In order to minimize the effects of the radiation, aluminum was chosen as the material of the plate as it has a lower emissivity. The backside heat loss is ignored. Natural convection boundary equations are solved using SIMPLE (the semi implicit method for pressure linked equations) and quadratic upwind. An accurate result was obtained by choosing the absolute value as $10^{-5}$ of the velocity at $\mathrm{x}$ and the velocity values at $y$ at the continuity under the monitor tab. For the calculation of the radiation heat transfer loss at the surface, surface to surface model was used. Figure 2 shows that the right wall is the symmetry wall in the domain.

\section{Boundary conditions}

The coordinate system was placed at the bottom center of the plate and coordinate $\mathrm{x}$ is chosen normal to the surface of the plate and coordinate $y$ is chosen along the length of the plate (see Figure 1). The ambient temperature is $300 \mathrm{~K}$ and it is quiescent air. Homogenic heat generation is occurring on the surface of the plate. Figure 2 shows that for the top and bottom walls of the domain, there are pressure outlet and pressure inlet conductions, where the pressure is $\mathrm{P}_{\mathrm{atm}}=101325 \mathrm{~Pa}$. The right wall is at symmetric condition at $\mathrm{x}=0.5 \mathrm{~m}$. The left wall of the domain has a constant heat flux of $1000 \mathrm{Wm}^{-2}$ at the surface of the plate $(\mathrm{x}=0)$. The wall of symmetry is chosen at a long distance so that the boundary layer which forms on the left wall where the heat transfer is taking place on the plate will not be affected. Figure 2 shows the dimensions.

Due to the non-slip condition at the plate-air interface, the air velocity equals the surface velocity. In other words, at $\mathrm{x}=0$, where the air comes in contact with the plate, the velocity of air is zero. Also, at $\mathrm{x}=0$, the temperature of the air at the heated surface equals the solid surface temperature. Outside the velocity boundary layer, the air is quiescent.

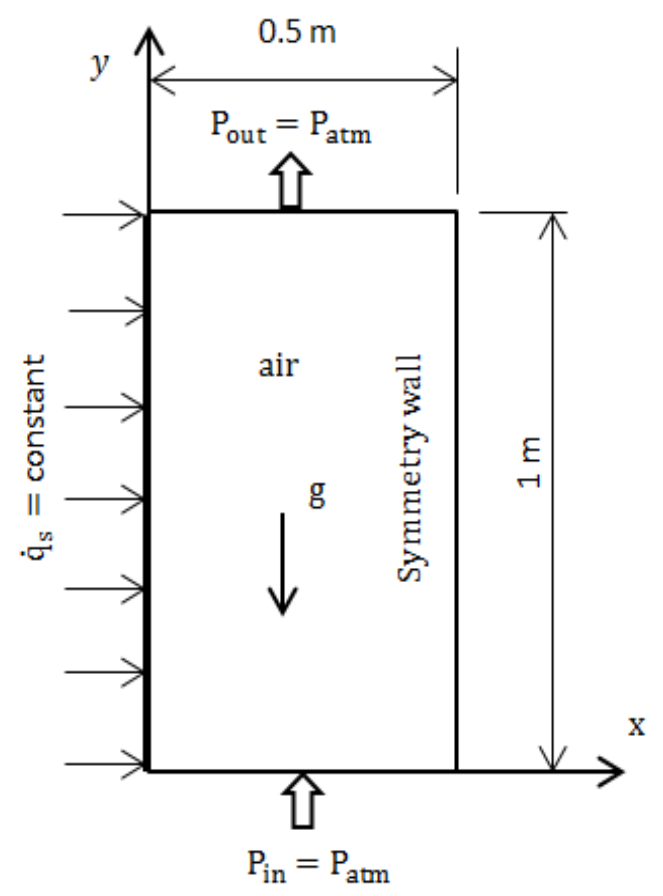

Figure 2. Schematic of the computational domain and boundary conditions. 


\section{Mesh Analysis}

Figure 3 shows that the mesh analysis was performed for the mesh sizes of 50x50,100x100, 200x200 and $300 \times 300$. As, the results were in consistent with those of Vliet [1], the mesh structure of 300x300 was used in this study. Figure 4 shows the mesh structure in the domain when the plate is placed vertically and $45^{\circ}$ inclined. Figure $4 \mathrm{~b}$ and $4 \mathrm{~d}$ show that mesh structure is denser in the domain that is close to the surface and not uniform. For the plate with $20^{\circ}$ inclination from the vertical, the same mesh structure was used.

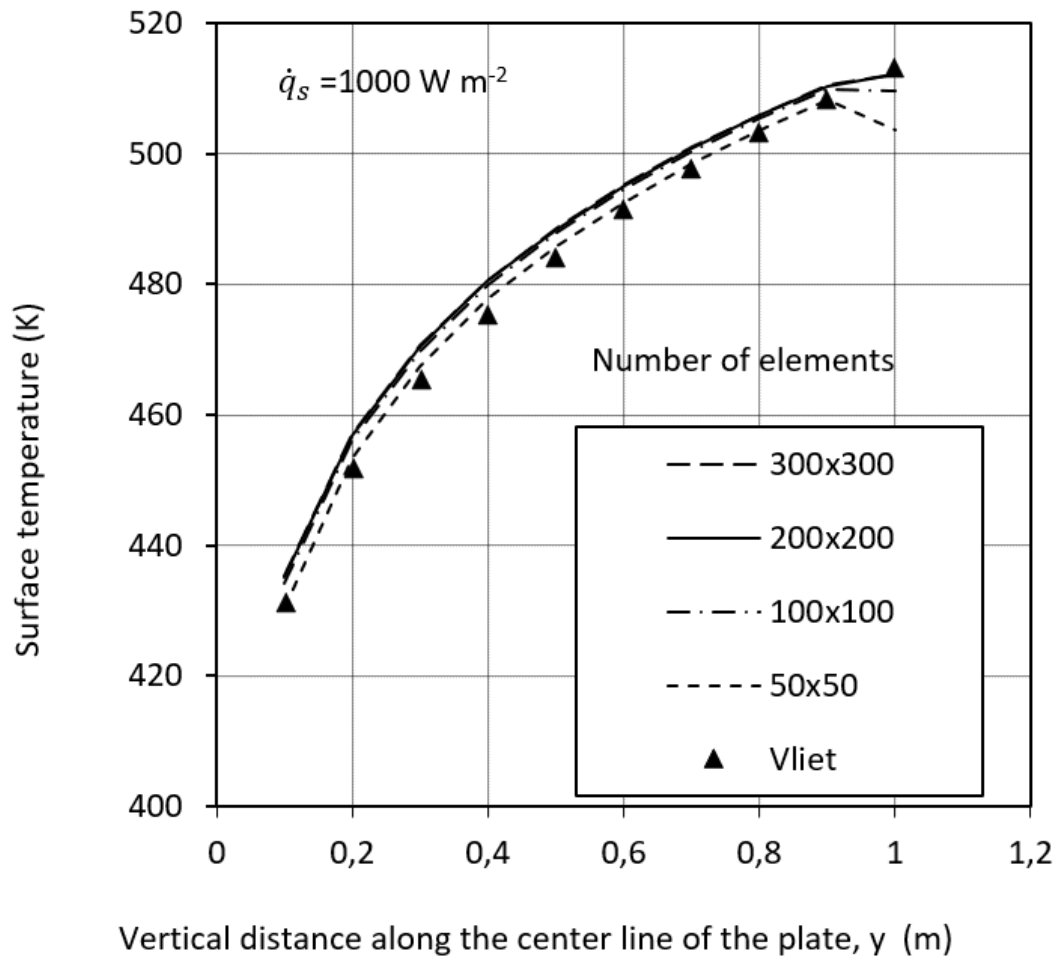

Figure 3. Comparison of the surface temperatures proposed by Vliet with those of computer analysis with radiation heat loss for different number of elements for vertical plate.

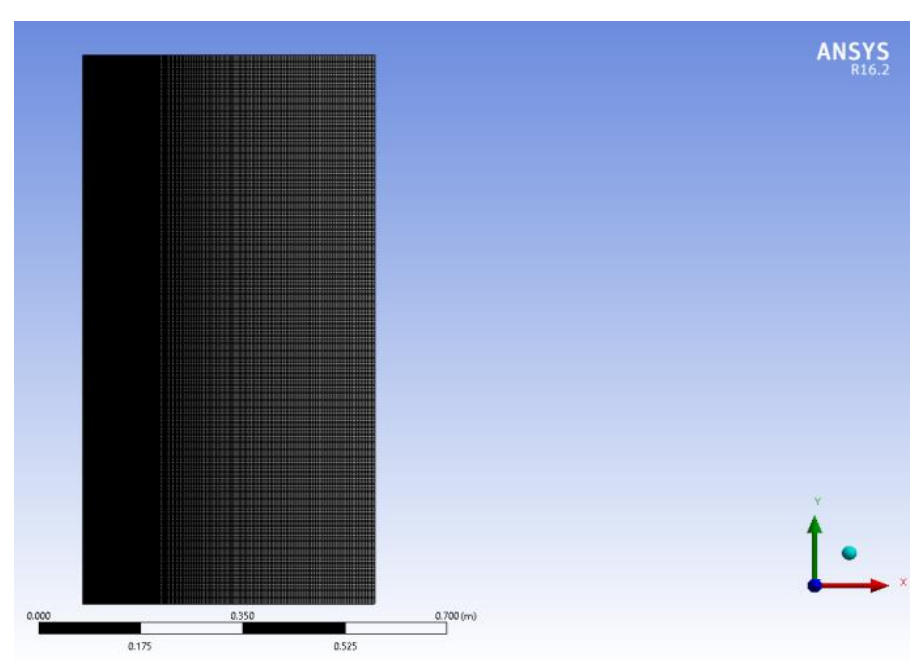

(a)

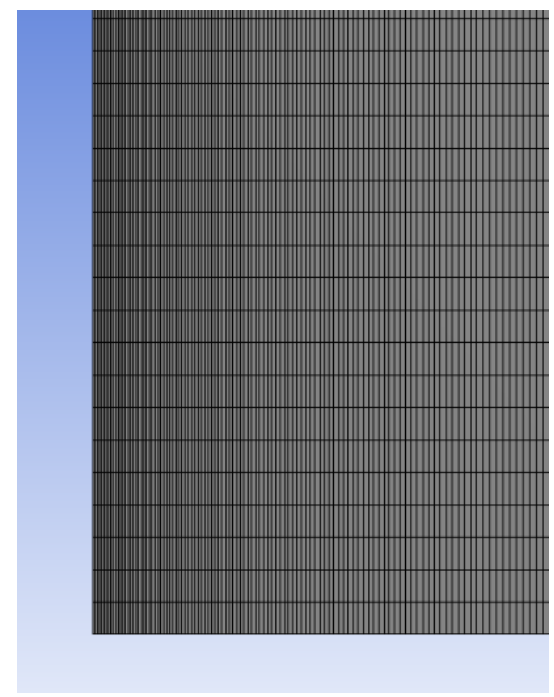

(b) 


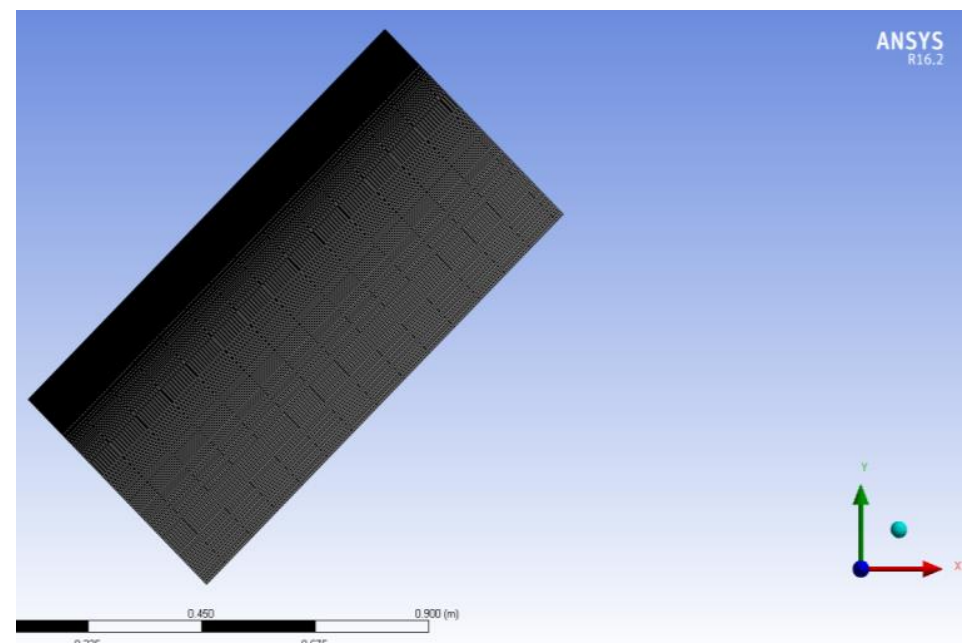

(c)

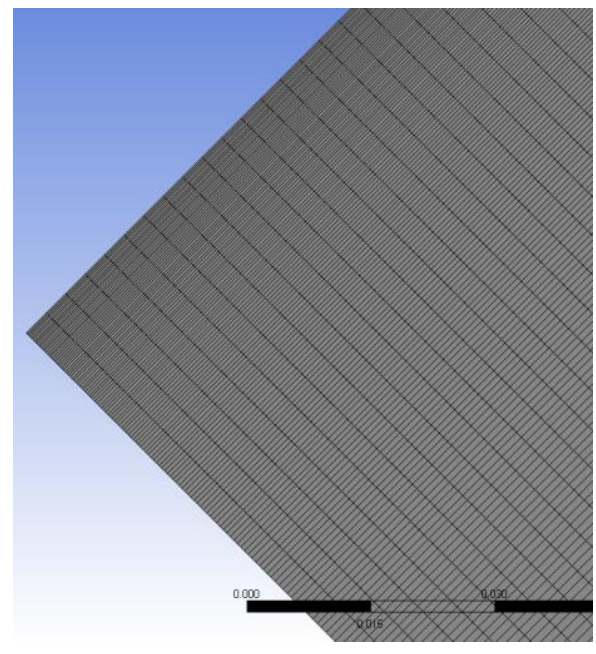

(d)

Figure 4. The mesh structure and mesh details in the domain: a) the whole domain of the vertical plate, b) a part of the domain that is close to surface; c) the whole domain of the $45^{\circ}$-inclined plate, d) a part of the domain that is close to surface.

\section{RESULTS AND DISCUSSION}

Figures 5 -10 show the results of the computational analyses on the vertical and on the downward-facing surface of $20^{\circ}$ - and $45^{\circ}$ - inclined plate at $1000 \mathrm{Wm}^{-2}$ constant heat flux. Figures 5-10 illustrate temperature counters and the velocity streamlines for each inclination angle, respectively.

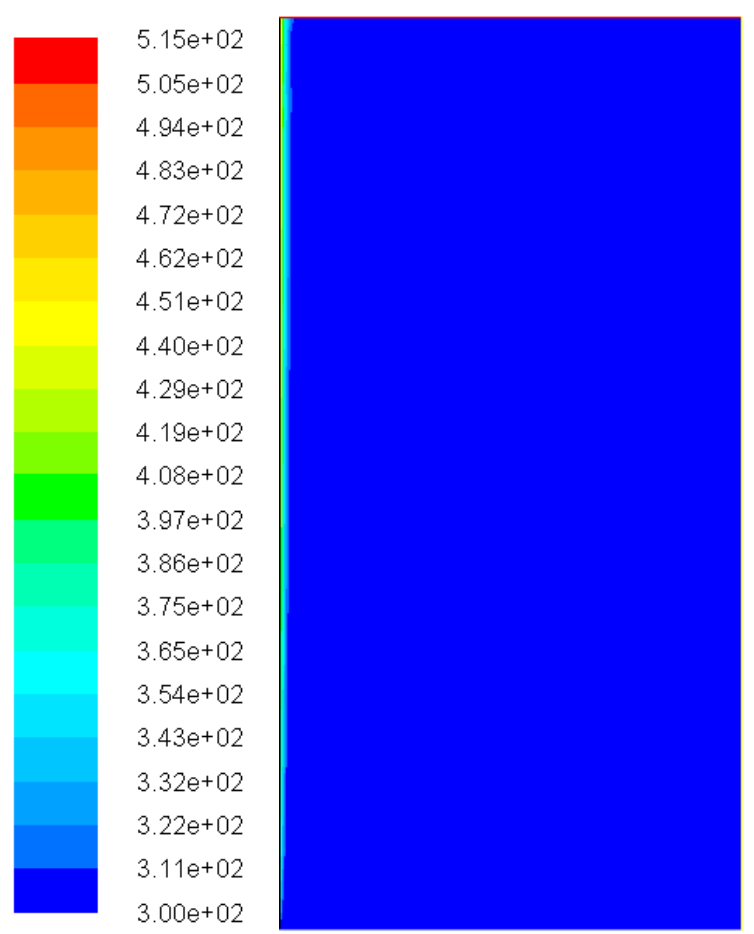

The surface temperature of the plate $[\mathrm{K}]$

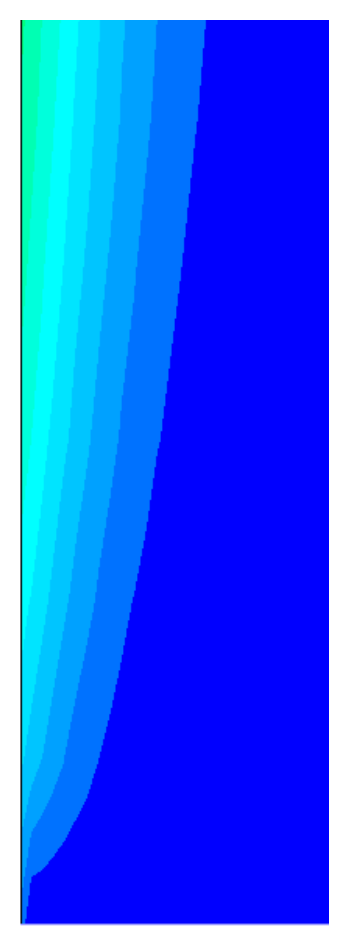

(b)

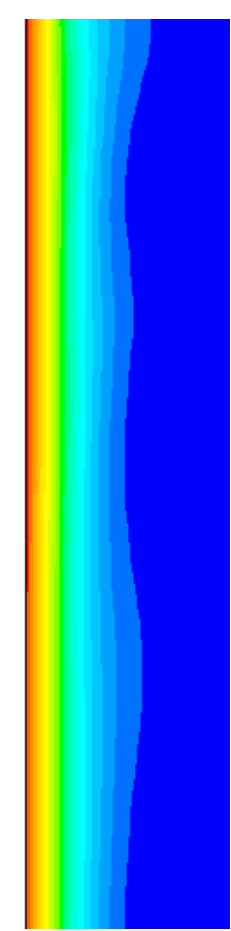

(c)

Figure 5. The temperature contours along the vertical plate: a) The complete domain; b) The bottom edge of the plate; c) The top edge of the plate. 
Journal of Thermal Engineering, Research Article, Vol. 4, No. 6, pp. 2432-2444, October, 2018

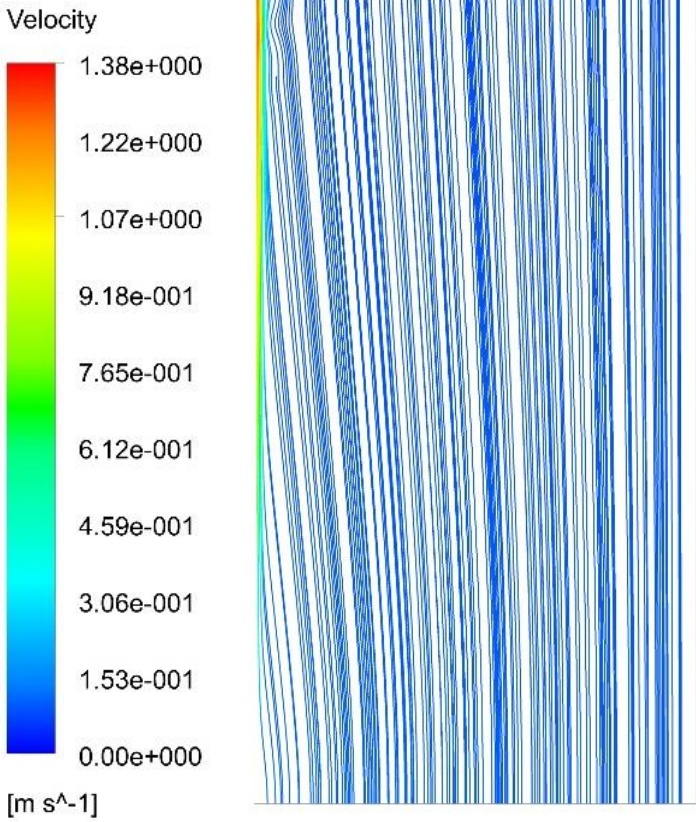

Figure 6. The velocity stream lines along the vertical plate.
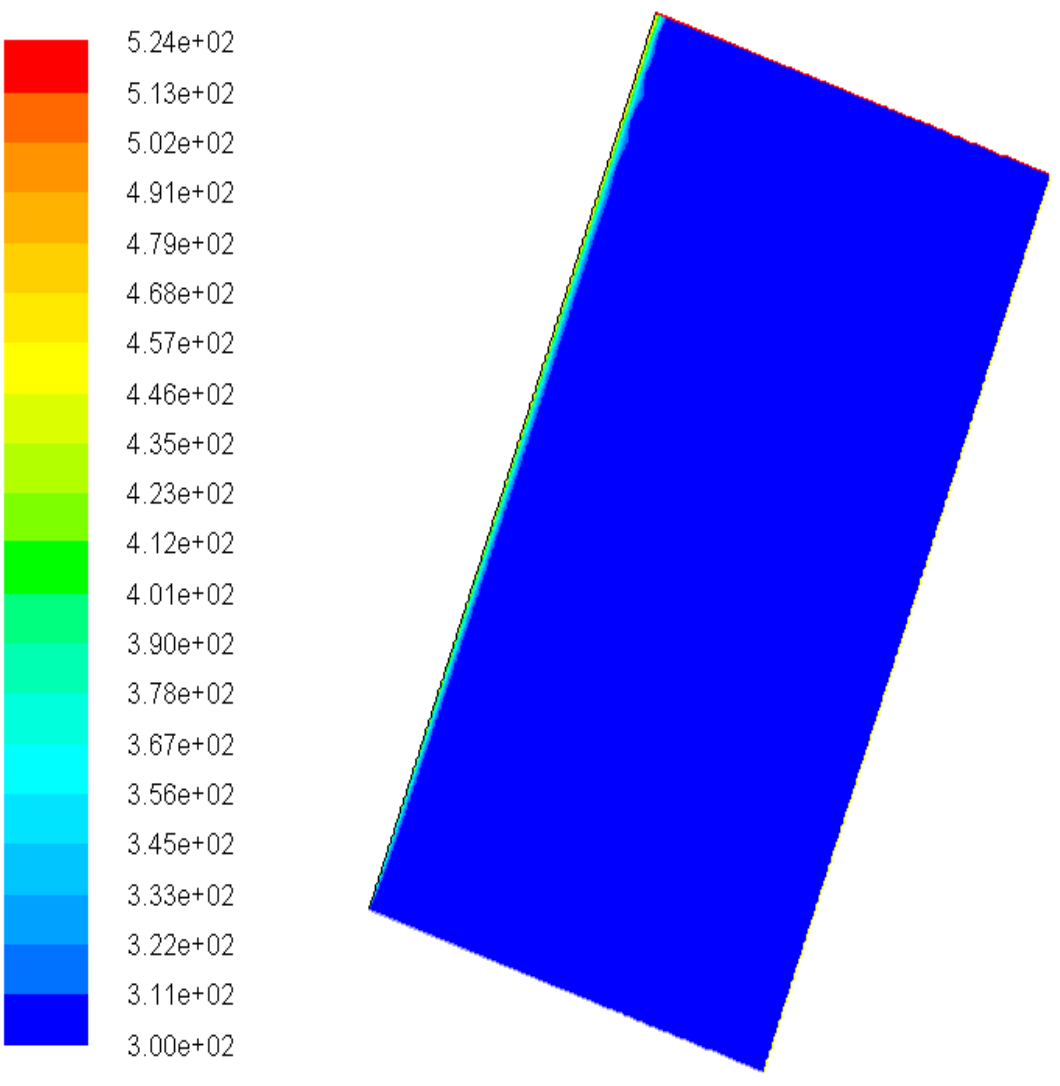

(a)

The surface temperature of the plate $[\mathrm{K}]$ 
(b)

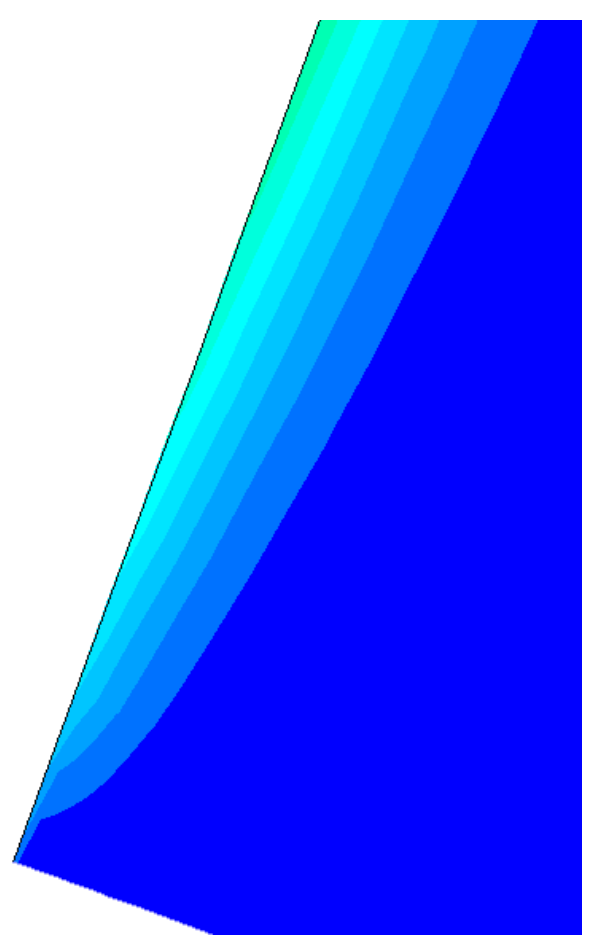

Figure 7. The temperature contours along the plate with $20^{\circ}$-inclination from the vertical: a) The complete

domain; b) The bottom edge of the plate; c) The top edge of the plate.

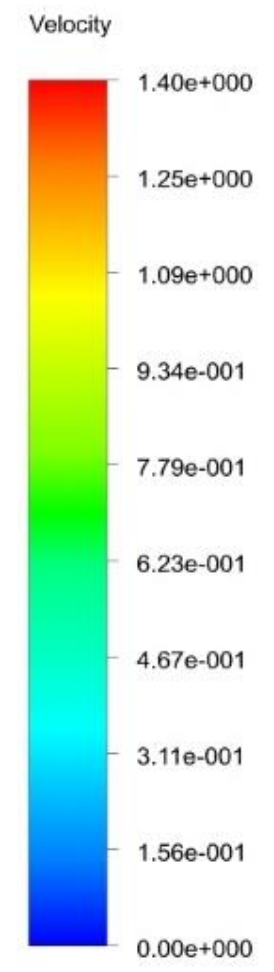

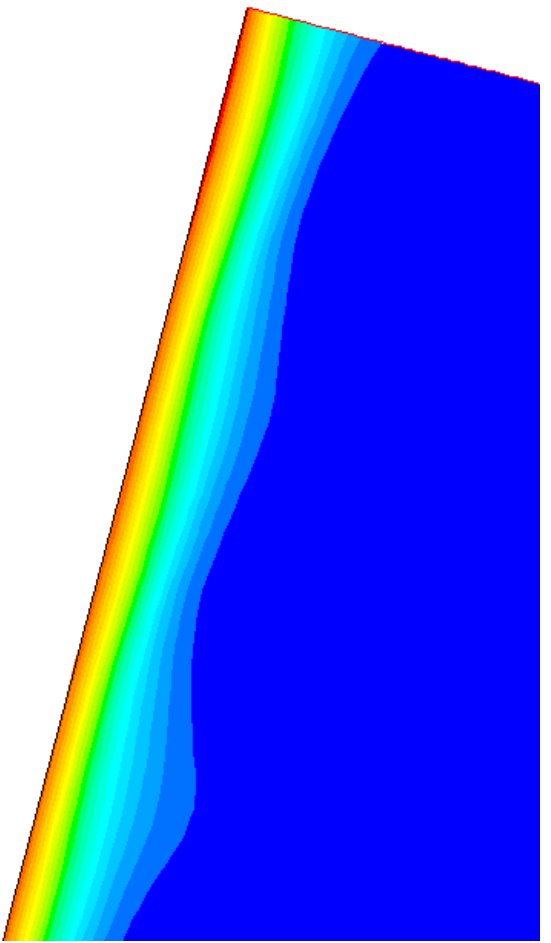

(c) $\left[\mathrm{m} \mathrm{s}^{\wedge}-1\right]$

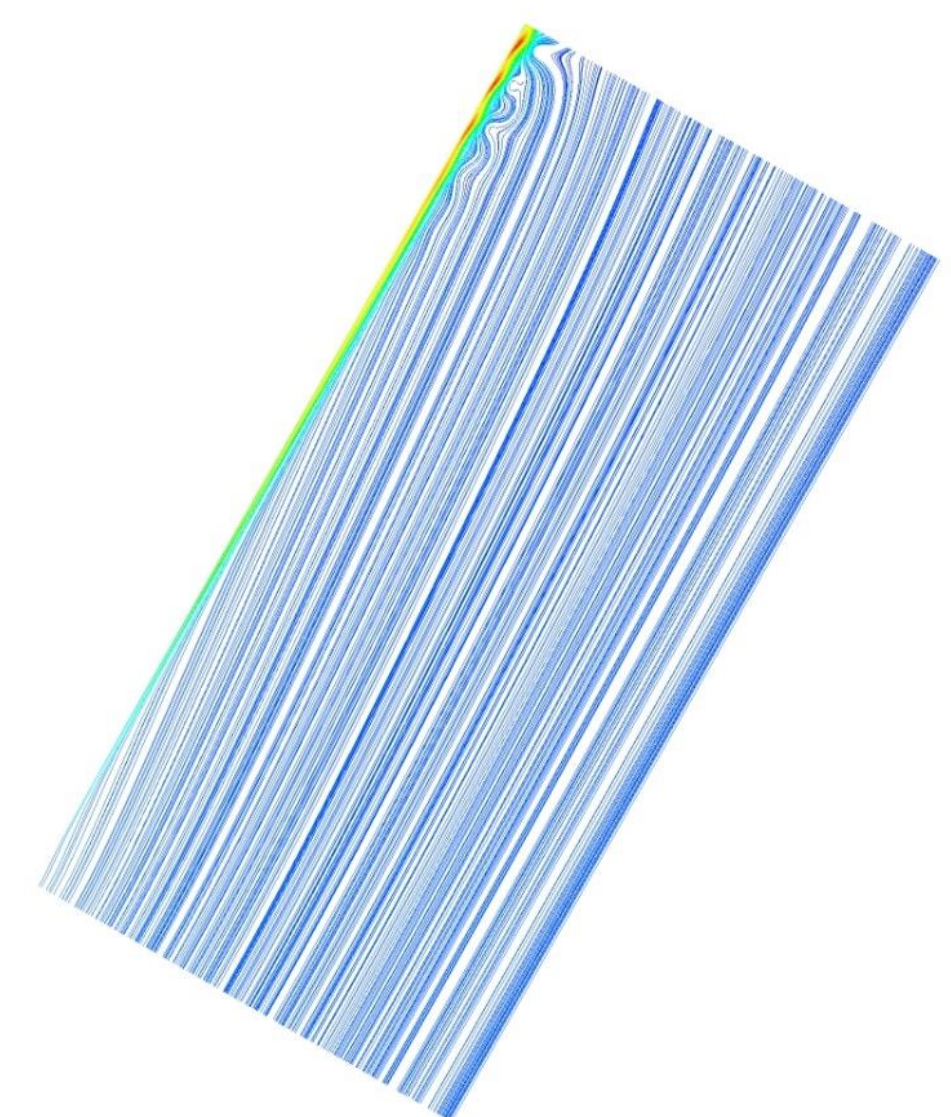

Figure 8. The velocity stream lines along the plate with $20^{\circ}$-inclination from the vertical. 
The air that comes in contact with the surface of the bottom edge of the plate with constant heat flux on the surface starts to heat and the low-density air starts to move upwards with the effect of right buoyancy forces. The upward-moving air along the plate gathers additional heat from the plate. At the same time, the temperature of air increases along the plate and the surface temperature of the plate increases also. The velocity stream lines give clues about the flow characteristics over the plate. As can be seen from Figures 6,8 and 10, there is a nonwavy laminar flow at the bottom edge of the plate while there is a wavy laminar flow at the domain which is close to the top edge of the plate. These are also clearly visible on the temperature counters along the plate, as shown in Figures 5, 7 and 9. For a vertically-placed plate, gravity vector is at the same direction with the plate but is downwards and buoyancy forces direct the fluid upwards. But, if the plate is inclined, buoyancy forces have both parallel and vertical components on the surface of the plate. A decrease in the buoyancy forces parallel to the surface, which is true for inclined plates, means a decrease in the velocity of the fluid along the plate, which means a relative decrease in convection heat transfer compared to a vertical plate. Thus, for the inclined plates, it is expected that the surface temperature of the plate would reach higher levels compared to vertical plates [17]. Therefore, when the plate is vertical, the surface temperature values are lower compared to inclined plates.

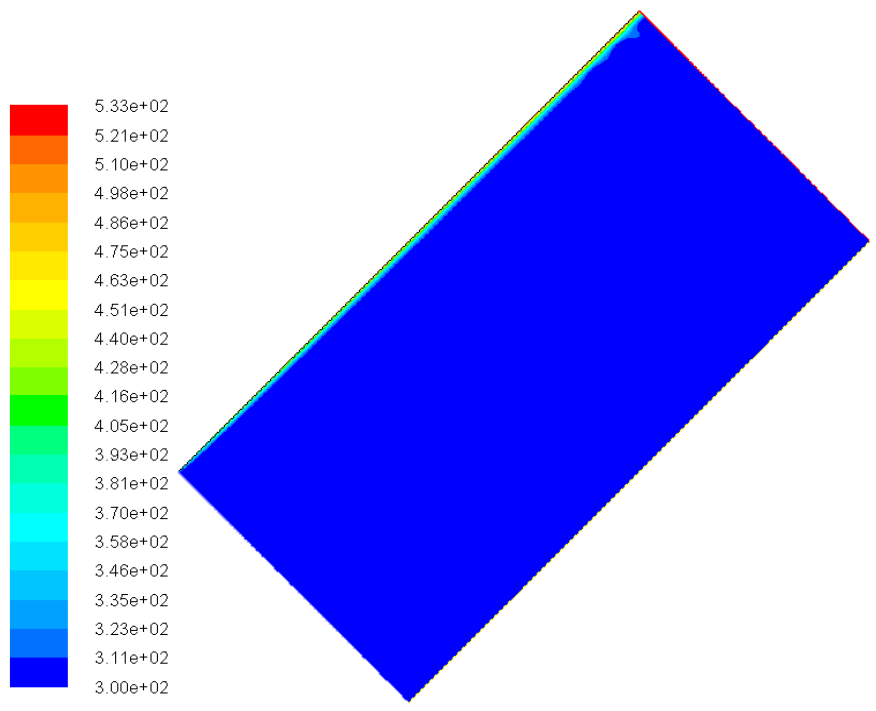

The surface temperature of the plate $[\mathrm{K}]$

(a)

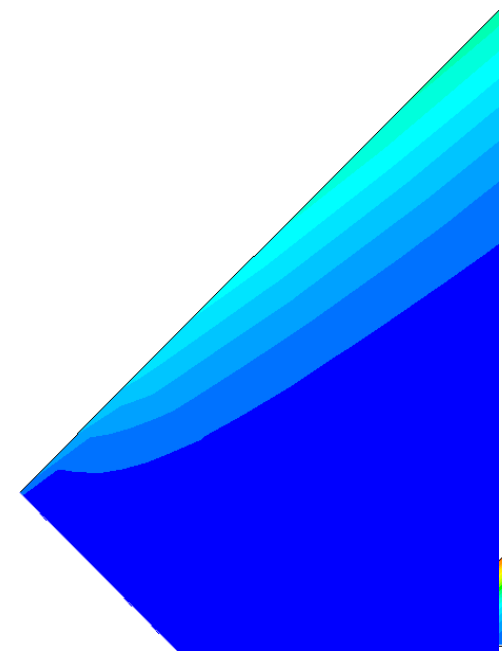

(b)

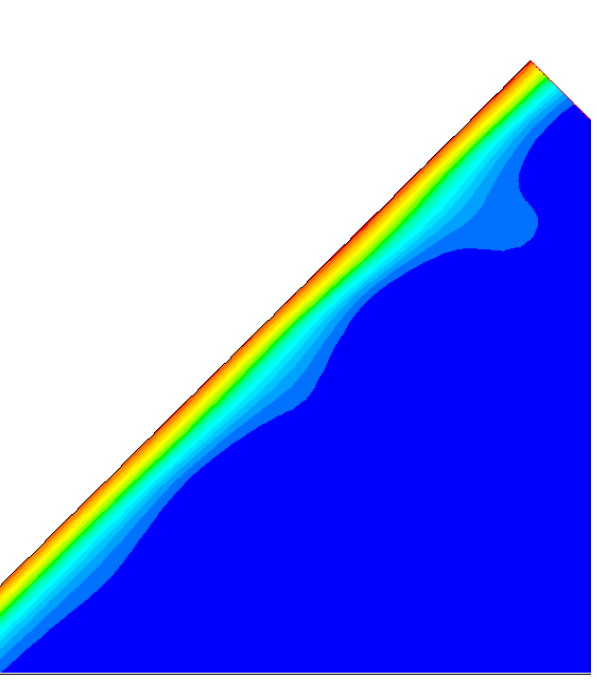

(c)

Figure 9. The temperature contours along the plate with $45^{\circ}$-inclination from the vertical: a) The complete domain; b) The bottom edge of the plate; c) The top edge of the plate. 


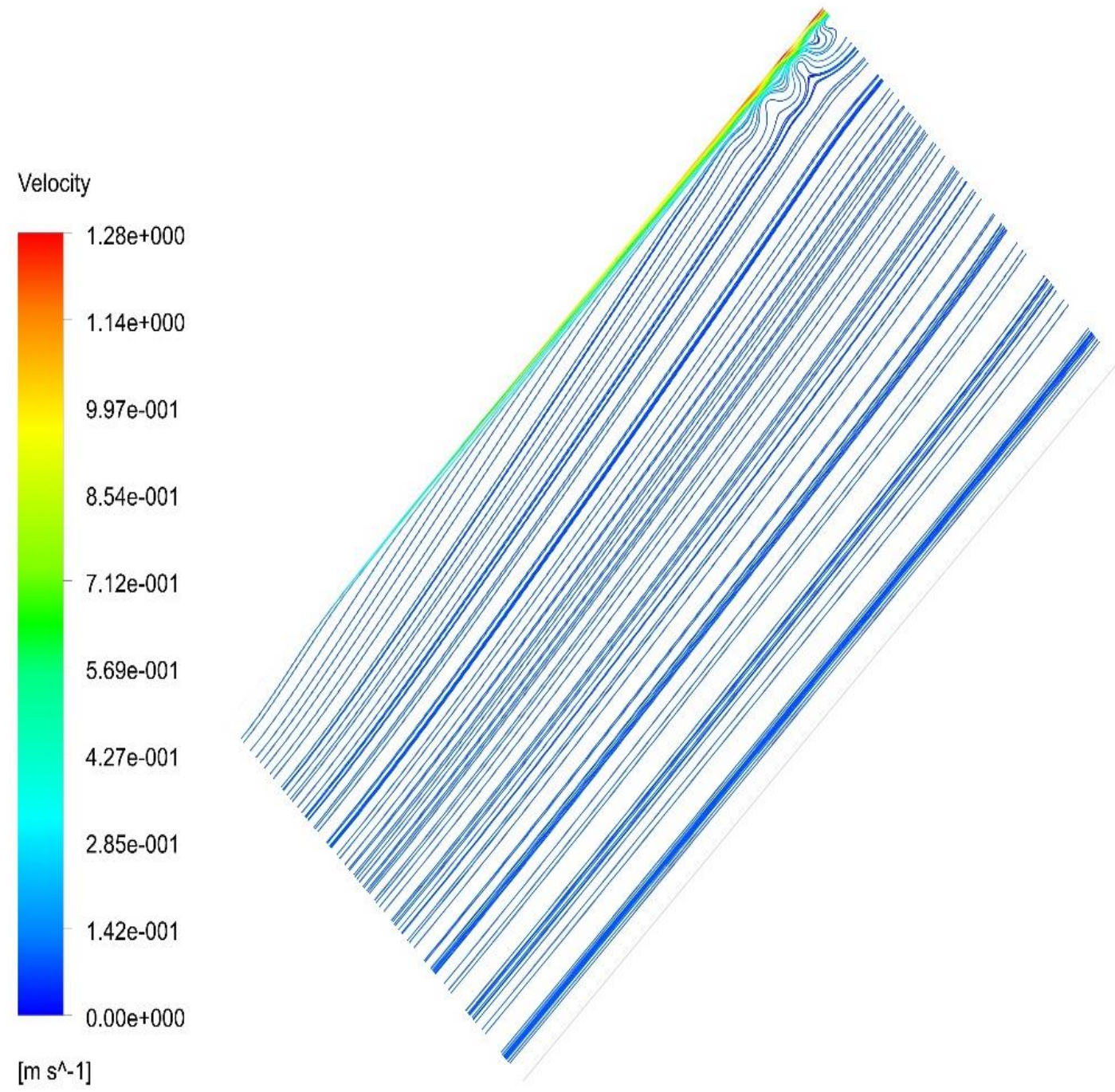

Figure 10. The velocity stream lines along the plate with $45^{\circ}$-inclination from the vertical.

A comparison of the plate surface temperature calculations using the correlation proposed by Vliet [1] to the computational analysis results was made and the results are shown for the vertical plate and for the inclination angles of $20^{\circ}$ and $45^{\circ}$ from the vertical in Figure 11. It is seen that the local temperature values along the plate rises from the bottom center line of the plate in direct proportion to $y^{1 / 5}$. The surface temperature values on the vertical plate are lower than those of the $45^{\circ}$ inclined plate. The temperature values at $20^{\circ}$ from the vertical are close to those of the plate at the vertical position. The temperature difference between the temperature on the upper edge of the center of the $45^{\circ}$-inclined plate and the temperature on the upper edge of the vertical center of the vertical plate is $17 \mathrm{~K}$. This shows that the plate when it is vertical is cooled better than when the plate is inclined. As a result of the fact that the y-component of the gravitational acceleration reduces to g.cos $\theta$, fluid velocities along the inclined plate are also reduced in comparison to the vertical plate and a consequent reduction in convection heat transfer to the surface occurs [17]. The same tendency was obtained by Fussey and Warneford [6], in their study where the plate surface temperature increased as the inclination angle from the vertical increased, as shown in Figure 11 .

Vliet [1] took the radiation effect into consideration in his experimental study. Also, in this study, the radiation effect is taken into consideration. It is predicted that the radiation heat loss from the surface of the plate when it is vertical is $65 \mathrm{~W}(6.5 \%)$ and it is $75 \mathrm{~W}(7.5 \%)$ when the plate is $45^{\circ}$ inclined. In this study, the radiation heat loss from the plate surface increases with an increase in inclination angle from the vertical, because the inclined plate has a higher surface temperature than the vertical plate. 


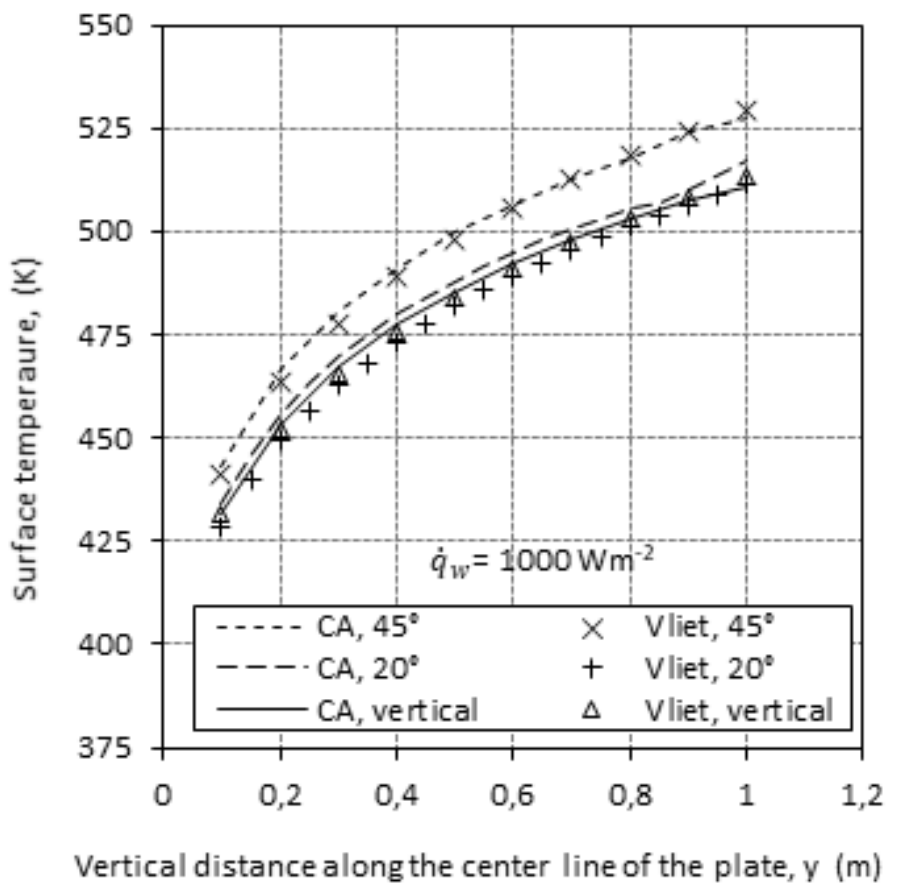

Figure 11. The comparison of correlation results of the surface temperature values along the center line of the plate to the results of the computational analyses.

Figure 11 shows that, in general, the results of the correlation proposed by Vliet [1] are in good agreement with the results of the computational analyses. While statistically investigating the computational analysis results, $\mathrm{R}$-squared approach was used for measuring deviations from the fit. The formula of R-squared is as follows:

$$
R^{2}=1-\frac{\sum\left(y_{i}-\hat{y}_{i}\right)^{2}}{\sum\left(y_{i}-\bar{y}\right)^{2}}
$$

where, $y_{i}$ is the actual data point and $\bar{y}$ is the average of $y_{i}$, and $\hat{y}_{i}$ is the estimated regression line $[18,19]$. In this study, the result of R-squared is $97 \%$.

\section{CONCLUSION}

In this study, natural convection heat transfer along the plate which was oriented vertical, and also $20^{\circ}$ and $45^{\circ}$-inclined from the vertical (downward-facing surface), at the constant heat flux of $1000 \mathrm{Wm}^{-2}$ was investigated. The plate was $1 \mathrm{~m}$ in height and $1 \mathrm{~m}$ in width. Along the vertical center line of the plate, the local temperature values for each $0.1 \mathrm{~m}$ were determined using the correlation proposed by Vliet [1] and computational analyses. The results show that local temperature values increase in distance along the plate. Relatively lower local temperature values were obtained in the vertical plate than the inclined plate. It was seen that the results of the correlation are in good agreement with the results of the computational analyses.

\section{NOMENCLATURE}

$g \quad$ gravity constant $\left[\mathrm{m} \mathrm{s}^{-2}\right]$

$G r^{*} \quad$ modified Grashof number, [-]

$h \quad$ convection heat transfer coefficient, $\left[\mathrm{W} \mathrm{m}^{-2} \mathrm{~K}^{-1}\right]$

$k$ thermal conductivity, [W $\left.\mathrm{W}^{-1} \mathrm{~K}^{-1}\right]$

$\mathrm{Nu} \quad$ Nusselt number, [-]

$P \quad$ pressure, $[\mathrm{Pa}]$

$\mathrm{Pr} \quad$ Prandtl number, [-]

$\dot{q} \quad$ heat flux, [ $\left.\mathrm{W} \mathrm{m}^{-2}\right]$ 


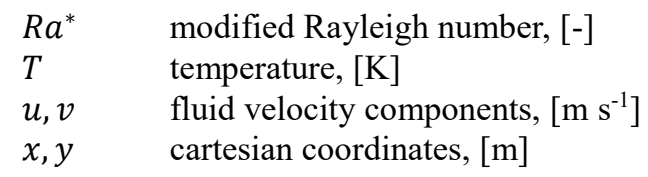

\section{Greek symbols}

\begin{tabular}{|c|c|}
\hline$\alpha$ & thermal diffusivity, $\left[\mathrm{m}^{2} \mathrm{~s}^{-1}\right]$ \\
\hline$\beta$ & volumetric thermal expansion coefficient, $\left[\mathrm{K}^{-1}\right]$ \\
\hline$\theta$ & plate angle, $\left[^{\circ}\right]$ \\
\hline$\mu$ & dinamic viscosity $\left[\mathrm{kg} \mathrm{m}^{-1} \mathrm{~s}^{-1}\right]$ \\
\hline$v$ & kinematic viscosity $\left[\mathrm{m}^{2} \mathrm{~s}^{-1}\right]$ \\
\hline$\rho$ & mass density, $\left[\mathrm{kg} \mathrm{m}^{-3}\right]$ \\
\hline \multicolumn{2}{|c|}{ Subscripts } \\
\hline atm & atmospheric \\
\hline f & film temperature conditions \\
\hline in & inlet \\
\hline out & outlet \\
\hline s & surface \\
\hline$y$ & local \\
\hline$\infty$ & ambient conditions \\
\hline
\end{tabular}

\section{REFERENCES}

[1] Vliet, G.C. (1969). Natural convection local heat transfer on constant-heat-flux inclined surface, Journal of Heat Transfer, 91(4), 511-517.

[2] Holman, J.P. (2101). Heat Transfer, Tenth Edition, McGrawHill.

[3] Vliet, G.C., Liu, C.K. (1969). An experimental study of turbulent natural convection boundary layers, Journal of Heat Transfer, 91(4), 517-531.

[4] Vliet, G.C., Ross, D.C. (1975). Turbulent natural convection on upward and downward facing inclined constant heat flux surfaces, Journal of Heat Transfer, 97(4), 549-554.

[5] Dotson, J.P. (1954).Heat transfer from a vertical plate by free convection, MS thesis, Purdue University.

[6] Fussey, D.E., Warneford, I.P. (1978). Free convection from a downward facing inclined flat plate, International Journal of Heat and Mass Transfer, 21, 119-129.

[7] Lim, C.K., Chung, B.J. (2015). Natural convection experiments on the upward and downward faces of inclined plates using an electroplating system, Heat Mass Transfer, 51, 713-722.

[8] Fahiminia, M., Naserian, M. M., Goshayeshi, H. R., Majidian, D. (2011). Investigation of natural convection heat transfer coefficient on extended vertical base plates, Energy and Power Engineering, 3, 174-180.

[9] Khan, W.A., Aziz, A. (2011). Natural convection flow of a nanofluid over a vertical plate with uniform surface heat flux, International Journal of Thermal Sciences, 50, 1207-1214.

[10] Lin, H.-T., Yu, W.-S., Yang, S.-L. (1989). Free convection on an arbitrarily inclined plate with uniform surface heat flux, Waerme- und Stroffübertragung 24, 183-190.

[11] Guha, A., Pradhan, K. (2017). A unified integral theory of laminar natural convection over surfaces at arbitrary inclination from horizontal to vertical, International Journal of Thermal Sciences 111, 475-490.

[12] Dubey, S., Sarvaiya, J.N., Seshadri, B. (2013). Temperature dependent photovoltaic (PV) efficiency and its effect on PV production in the word-a review, Energy Procedia 33, 311-321.

[13] Bejan, A. (1984). Convection heat transfer, John Wiley and Sons.

[14] Wilson, M.J., Paul, M. C. (2011). Effect of mounting geometry on convection occurring under a photovoltaic panel and the corresponding efficiency using CFD, Solar Energy, 85, 2540-2550.

[15] Saha, S.C. (2008). Natural convection adjacent to an inclined flat plate and in an attic space under various thermal forcing conditions. PhD thesis, James Cook University, http://eprints.jcu.edu.au/12138.

[16] ANSYS Fluent Theory Guide, (2013).15317, November.

[17] Incropera, F.P., DeWitt, D.P. (1996). Fundamentals of Heat and Mass Transfer, Fourth Edition, John Wiley and Sons.

[18] https://newonlinecourses.science.psu.edu/stat501/node/255/

[19] Tari, I., Mehrtash, M. (2013). Natural convection heat transfer from inclined plate-fin heat sinks, International Journal of Heat and Mass Transfer 56, 574-593. 